\title{
A atualidade do diagnóstico e da crítica de Darcy Ribeiro (1922-1997) à educação brasileira
}

The originality of Darcy Ribeiro's (1922-1997) diagnosis and criticism on education in Brazil

La actualidad del diagnóstico y de la crítica de Darcy Ribeiro (1922-1997)

a la educación brasileña

Celso José Martinazzo

Universidade Regional do Noroeste do Estado do Rio Grande do Sul (Brasil)

http://lattes.cnpq.br/4786467654675694

https://orcid.org/0000-0001-9995-8224

martinazzo@unijui.edu.br

Sidinei Pithan da Silva

Universidade Regional do Noroeste do Estado do Rio Grande do Sul (Brasil)

http://lattes.cnpq.br/8709044822441696

http://orcid.org/0000-0001-6400-4631.

sidinei.pithan@unijui.edu.br

Hedi Maria Luft

Universidade Regional do Noroeste do Estado do Rio Grande do Sul (Brasil)

http://lattes.cnpq.br/8722880713063414

https://orcid.org/0000-0002-9691-1268

hedi@unijui.edu.br

\section{Resumo}

Darcy Ribeiro, destacado antropólogo, educador e político brasileiro, é reconhecido por sua preocupação com a questão indígena e pela sua luta em defesa de uma educação pública e democrática. Nos seus escritos podemos encontrar subsídios sobre a realidade latino-americana e sobre a participação dos índios, negros e mestiços no processo de formação e desenvolvimento sociocultural do povo brasileiro, nos quais menciona, com muita propriedade, as causas históricas que estão na gênese dos níveis de desenvolvimento e desigualdade no Brasil. Nosso foco, neste texto, é explicitar o diagnóstico e a crítica de Darcy Ribeiro em relação à educação e à escola pública brasileira, tomando como referência principal o seu livro Nossa escola é uma calamidade, escrito em 1984, no qual analisa a situação da educação e da escola pública brasileira no final do século 20. A partir das provocações do autor, buscamos considerar os avanços e recuos da atual educação brasileira em relação às problemáticas apresentadas no final do século 20.

Palavras-chave: Darcy Ribeiro. Escola pública. Democratização da educação. 


\begin{abstract}
Darcy Ribeiro, a distinguished Brazilian anthropologist, educator and politician, is recognized for his concern with the indigenous issue and his struggle to defend a public and democratic education. In his writings, we can find references to the Latin American reality and to the participation of Indians, blacks and mestizos in the process of formation and socio-cultural development of the Brazilian people, in which he mentions very well the historical causes that are at the genesis of the levels of development and inequality in Brazil. Our focus in this text is to make explicit the diagnosis and criticism of Darcy Ribeiro in relation to education and the Brazilian public school, taking as main reference his book Our school is a calamity, written in 1984, in which it analyzes the situation of education and of the Brazilian public school at the end of the 20th century. From the author's provocations, we sought to consider the advances and setbacks of the current Brazilian education in relation to the problems presented at the end of the 20th century.
\end{abstract}

Keywords: Darcy Ribeiro. Public school. Democratization of education.

\title{
Resumen
}

Darcy Ribeiro, destacado antropólogo, educador y político brasileño, es reconocido por su preocupación con la cuestión indígena y por su lucha en defensa de una educación pública y democrática. En sus escritos podemos encontrar subsidios sobre la realidad latinoamericana y sobre la participación de los indios, negros y mestizos en el proceso de formación y desarrollo sociocultural del pueblo brasileño, en los que menciona, con mucha propiedad, las causas históricas que están en la génesis de los niveles de desarrollo y desigualdad en Brasil. Nuestro enfoque, en este texto, es explicitar el diagnóstico y la crítica de Darcy Ribeiro en relación a la educación y a la escuela pública brasileña, tomando como referencia principal su libro Nuestra escuela es una calamidad, escrito en 1984, en el cual analiza la situación de la educación y de la escuela pública brasileña a finales del siglo 20. A partir de las provocaciones del autor, buscamos considerar los avances y retrocesos de la actual educación brasileña en relación a las problemáticas presentadas a finales del siglo 20.

Palabras-clave: Darcy Ribeiro. Escuela pública. Democratización de la educación. 


\section{Considerações iniciais}

No presente texto temos como foco analisar e compreender a visão de Darcy Ribeiro ${ }^{1}$ em relação à situação da educação brasileira no final do século 20 , sobretudo da escola pública, bem como as suas lutas e contribuições para uma educação escolar mais democrática. Na introdução do seu livro Nossa escola é uma calamidade, Ribeiro escreve: "A educação é uma das causas de minha vida. Por isso mesmo, falo dela sempre emocionado, com o coração na boca" (1984, p. 7). Embora um otimista e esperançoso em relação a um futuro positivo para o Brasil, em um horizonte mais amplo o que ele pretende com a obra é nos encher de indignação e nos despertar para o estágio precário da educação brasileira, principalmente nos níveis iniciais (escola primária). ${ }^{2}$

Darcy Ribeiro é considerado um dos maiores intelectuais da história recente do Brasil, pela originalidade e qualidade do seu trabalho, pelas pesquisas e pelas produções como antropólogo, educador e escritor. Dedicou sua vida a observar e registrar as necessidades do povo brasileiro, em especial das camadas mais necessitadas, e lutou por uma vida mais justa e igualitária para todos a partir da educação. O educador, ao perceber a precariedade do ensino no Brasil, decidiu envolver-se de forma integral na organização e gestão da educação. Sua conclusão é a de que os problemas de nossa educação não são nada simples; e, se fossem, seriam resolvidos. Seu ponto de partida é o ideário escolanovista, com forte influência do educador americano John Dewey e da figura do brasileiro Anísio Teixeira. Ribeiro seguiu o ideário escolanovista na condição de educador e herdeiro da Escola Nova e, juntamente com Anísio Teixeira, lutava por uma escola pública democrática e laica.

O antropólogo em questão, igualmente, dedicou grande parte de sua vida a pesquisar e a escrever sobre a formação sociocultural do Brasil, em especial sobre a realidade indígena. Nos seus escritos podemos encontrar muitos subsídios sobre a realidade latino-americana, bem como sobre a participação dos índios, negros e mestiços no processo de formação e desenvolvimento sociocultural do povo brasileiro. Algumas de suas obras, como O Processo Civilizatório (1998), As Américas e a Civilização: processo de formação e causas do desenvolvimento cultural desigual dos povos americanos (2007), Os índios e a civilização (2017), O Dilema da América Latina: estruturas do poder e forças insurgentes (1979) e Os brasileiros: Teoria do Brasil (1975), foram escritas na década de 80 e são consideradas, por ele próprio, como estudos de antropologia da civilização. Essas e muitas publicações do autor, as quais foram traduzidas para outros idiomas por seu caráter de ineditismo, permitem-lhe constituir fundamentos teóricos que ajudam a tornar o Brasil explicável e, por conseguinte, alimentam sua obra principal, que é O Povo Brasileiro: a formação e o sentido do Brasil (2014), escrita em 1995.

São essas interrogações radicais que movimentam a interpretação do autor na obra sobre o povo brasileiro: quem somos nós, os brasileiros? O que é o Brasil? Movido pela ambição de "desnaturalizar" a constituição desigual da sociedade brasileira, o autor esboça uma problemática e uma hipótese de trabalho e de pesquisa que procura evidenciar os lugares subalternos a que foi condicionada a grande maioria do povo brasileiro. Está em questão na obra, portanto, não apenas um desfile alegórico das etnias e dos vários brasis existentes, mas,

\footnotetext{
${ }^{1}$ Nasceu em Montes Claros (MG), em 1922. Exerceu a função de escritor, político, antropólogo e educador. Morreu em 1997, em Brasília, aos 74 anos, vítima de câncer. Segundo Gomes (2005), Darcy recebeu a influência de três grandes personalidades que marcaram sua trajetória de vida. Assim, como naturalista, foi influenciado pelo marechal Cândido Mariano da Silva Rondon; Anísio Spínola Teixeira o inspirou como educador; e a sua ação política foi marcada pela figura de Leonel de Moura Brizola.

${ }^{2}$ A escola primária, na generalidade das jurisdições escolares, se tornou uma referência que envolve a base de uma educação escolar oficial, ou seja, o nível elementar de escolarização. Mesmo não sendo mais a nomenclatura, desde 1971, na legislação brasileira, ainda é menção recursiva para identificar o processo de formação inicial.
} 
fundamentalmente, a constituição das relações de poder entre diferentes classes sociais e grupos culturais e étnicos na feitura do Brasil.

Darcy Ribeiro parece querer pensar o problema do Brasil: a) na interface da cultura, e então sinalizar para o problema do eurocentrismo; e b) na interface da economia, e então sinalizar para as formas e os diferentes significados da dominação de classe que se estabeleceram no Brasil durante os vários ciclos econômicos: do pau-brasil, do açúcar, da mineração, da pecuária, da agricultura, do café, do algodão, da borracha, da industrialização, da soja e do trigo.

O desafio de escrever a obra O Povo Brasileiro: a formação e o sentido do Brasil (2014), provoca-o a fazer uma crítica ao processo de civilização, uma vez que situa o movimento do mundo como um processo condicionado ou produzido pela expansão da cultura europeia, a qual silenciou a voz e as manifestações culturais de outros povos. $\mathrm{O}$ foco gira em torno da questão da cultura. Os conceitos de matrizes étnicas, enfrentamento dos mundos, processo civilizatório, criatório de gente, cunhadismo, cor, preconceito, raça, transfiguração étnica, brasil crioulo, caboclo, sertanejo, caipira, sulino remetem-nos para esta dimensão cultural constitutiva da história social e política do Brasil.

Para fins deste estudo, porém, vamos dar ênfase a sua importante obra - Nossa escola é uma calamidade - escrita em 1984, na qual analisa a realidade da educação e da escola pública brasileira de sua época. Também retomaremos alguns textos em que o escritor trata da elaboração da Lei de Diretrizes e Bases da Educação Nacional $n^{\circ}$ 9.394/96, os quais foram recentemente publicados no livro Educação como prioridade 3 (2018), que reúne seus textos. Esta incursão nos permite compreender como Darcy Ribeiro assume o problema educacional como uma questão central e prioritária para o desenvolvimento do Brasil como nação, e como ela se torna sua bandeira de luta na continuidade da ação de Anísio Teixeira. De outra parte, nos mostra o legado de um pensador que participou dos embates na década de 50, bem como na década de 90, sobre as Leis de Diretrizes e Bases da educação brasileira.

Embora tenha recebido críticas por não ter se dedicado, exclusivamente, à antropologia, Darcy Ribeiro ampliou seu campo de investigação e atuação produzindo obras literárias e textos sobre temas sociais, culturais e educacionais. Escreveu cerca de 30 livros com ênfase nessas temáticas. Seu desafio maior, no entanto, sempre foi o de elucidar e escrever como surgiu, qual o sentido, a formação, e quais as etapas da evolução sociocultural do Brasil.

Neste sentido, Ribeiro é antropólogo, por pensar sobre o homem e a cultura e por ter buscado compreender a experiência de vida dos povos indígenas que constituem o Brasil; é historiador, por pensar a gênese histórica e civilizacional do homem, da cultura e da sociedade; é sociólogo, por pensar a estruturação de uma sociedade em sua interface com a vida econômica, social, cultural, histórica e política; é filósofo crítico, por se perguntar acerca de quem somos identitariamente e buscar problematizar a forma como fomos descritos pela historiografia oficial; e, por fim, é político, por entender que a história (e o curso do mundo e das sociedades humanas) está sendo, permanentemente, escrita pelos homens.

No campo de sua atuação pública como educador, vale o destaque pelo seu empenho em criar e defender uma escola à altura do momento civilizacional em que vivemos. Algo que remonta às aspirações do Manifesto dos Pioneiros da Educação Nova, em 1932, e ao Manifesto dos Educadores Mais uma vez Convocados, de 1959. A projeção de Darcy Ribeiro, um dos educadores mais atuantes no campo da educação pública, desafia-nos a pensar a continuidade da educação brasileira no século 21. Para tanto, arriscamos entender seu diagnóstico da educação no século 20 para, em seguida, analisarmos seu pensamento em relação à questão da Lei de Diretrizes e Bases da Educação Nacional, o que nos abre as portas para retomar os problemas da educação e da escola brasileira na contemporaneidade.

\footnotetext{
${ }^{3}$ O livro Educação como prioridade, publicado em 2018, foi organizado por Lucia Velloso Mauricio e reúne vários textos de Darcy Ribeiro. É uma coletânea que mostra o pensamento do educador sobre diferentes temáticas, bem como algumas de suas ações no campo da educação.
} 


\section{A educação brasileira no final do século 20}

Em Nossa Escola é uma Calamidade (1984), o autor faz um fiel retrato da realidade da educação brasileira no final do século 20. Começa por manifestar seu espanto com a organização escolar por abranger uma rede tão ampla e com um número imenso de alunos que se deslocavam diariamente para frequentar as escolas. Ao mesmo tempo, manifestava sua indignação com o percentual altíssimo de pessoas que eram analfabetas, iletradas ou analfabetas funcionais (vamos comentar, na segunda parte, alguns dados estatísticos sobre essa realidade).

Darcy Ribeiro procurava uma explicação para esse grave panorama e questionava-se sobre quais poderiam ser as causas deste enorme fracasso escolar: "como é que o Brasil consegue ser tão ruim em educação?” (RIBEIRO, 1984, p. 22). E, tentando não ser pessimista, ele se perguntava: Por que a educação no Brasil e no Rio de Janeiro é tão precária? (idem, p. 36). As possíveis respostas para as causas de nosso fracasso escolar, segundo ele, "[...] residem, provavelmente nas camadas mais profundas do nosso ser nacional e dizem respeito ao caráter de nossa sociedade" (idem, p. 36), que se caracteriza pela desigualdade e pela injustiça social. A sua Pequena Utopia é alcançar o básico que outros países em igual, ou até menor nível de desenvolvimento, já alcançaram: emprego, alimentação, saúde e curso primário para todas as crianças. Disso, no entanto, estamos sendo impedidos

[...] porque o projeto classista de organização do nosso país é hostil a seu povo. Não a alcançou porque, entre nós, tudo se faz para impedir a realização das potencialidades do povo brasileiro. O que buscaram e buscam os que ditam e regem a nossa política econômica não é atender às necessidades mínimas da população. É maximizar os lucros empresariais. Nossas classes dirigentes trabalham muito mais para impedir que a Pequena Utopia se cumpra do que para que ela se realize. Entretanto, seu cumprimento é o requisito indispensável para o florescimento da civilização livre e solidária que havemos de ser (idem, p. 8).

Ele fazia referência a duas experiências que considerava positivas de educação popular e que poderiam servir de exemplo para a superação do nosso descalabro educacional: primeiro, a obra de Martinho Lutero, na Alemanha, que elevava a leitura ao plano da oração (ler é a forma suprema de rezar), e a segunda iniciativa vem de Napoleão, na França. A educação napoleônica se funda na importante função do professor primário ${ }^{4}$, que deve estar preparado para “[...] desasnar os franceses e capacitá-los para o exercício da cidadania" (idem p. 38).

O sociólogo aponta o crescimento populacional desenfreado como uma das principais causas que estariam produzindo esses resultados desastrosos. Na época, a população brasileira já girava em torno de 150 milhões de habitantes e com tamanho crescimento, segundo ele, é impossível alcançar o mínimo de qualidade desejada nos serviços prestados pelo poder público. A rede escolar é incapaz de atender à totalidade da demanda. Os dados mais preocupantes revelavam que, conforme o censo de 1970, cerca de $42 \%$ dos jovens que não sabiam ler e nem escrever residiam nas zonas rurais, e $10 \%$ nas cidades (RIBEIRO, 1984, p. 13).

O político espantava-se ainda mais com a gravidade do problema educacional ao comparar os dados estatísticos do Brasil com os índices dos países próximos, como Uruguai, Paraguai e Chile, mas, especialmente, Cuba. Em uma de suas pesquisas pôde constatar que

\footnotetext{
${ }^{4}$ Professor primário com a função de atender as exigências de uma educação elementar.
} 
muitos brasileiros nunca haviam sequer frequentado uma escola e, dentre os alunos que a frequentavam, a média de aprovação era extremamente baixa. De acordo com ele, "[...] apenas $30 \%$ das crianças alcançam a quarta série, que corresponde àquele mínimo de domínio da escrita e da leitura que habilita uma pessoa a operar, com eficácia, dentro de uma sociedade letrada" (1984, p.16).

Ele alertava, ainda, que a escola primária ${ }^{5}$ era seletiva e elitista, pois, mesmo que grande parte das crianças que a escola recebia era de classes populares, essas eram educadas da mesma forma que as crianças dos setores privilegiados. A exclusão ocorria, portanto, não apenas por falta de escola e de possibilidade de frequentá-la, mas pela problemática da desigualdade e da exclusão social que ocorre em escala mais ampla. Mesmo nas áreas mais ricas do país, como no caso da cidade do Rio de Janeiro, que recebera uma "rede escolar frondosa e um professorado multitudinário", nosso pesquisador percebeu que o quadro excludente (de evasão escolar) se reproduzia e o desempenho educacional era "menos do que medíocre" (RIBEIRO, 1984, p.16). Ele constatou, neste caso, que "em 1975 para mil crianças matriculadas na primeira série, 486 alcançaram a segunda série em 1976; 464 a terceira série em 1977, e 417 a quarta série em 1978” (IBIDEM). Está em questão, para Darcy Ribeiro, a partir desta realidade, a dificuldade com a qual os professores se deparam ao lidar com as crianças e jovens das classes populares quando estes adentram a escola.

Este ângulo da questão merece especial atenção. A criança das classes abandonadas que tem em casa quem estude com ela, algumas horas extras, enfrenta galhardamente esse regime escolar em que quase não se dá aulas. Ele só penaliza, de fato, a criança pobre oriunda de meios atrasados, porque ela só conta com a escola para aprender alguma coisa. Aqui está o fulcro da questão: nossa escola fracassa por seu caráter cruelmente elitista (RIBEIRO, 2018, p. 21).

O alvo da preocupação educacional emerge na obra deste pesquisador como que relacionado com a questão do valor da escola para as crianças pobres e da razão de seu fracasso. Ele procura, ao fazer uma análise do panorama histórico e societário brasileiro, evidenciar como a ideia do fracasso escolar não pode culpabilizar o aluno pobre, ou mesmo declarar simplesmente que estas "deficiências" vêm de casa (RIBEIRO, 1984, p.19). Darcy Ribeiro entendia que a escola não estava sabendo acolher e reconhecer as crianças provindas de classes pobres e isso explicava, em grande parte, os resultados tão negativos. O caráter seletivo e elitista faz com que a criança pobre seja rejeitada e, por outro lado, a com melhores condições financeiras é vista como alguém que tem futuro e condições de aprender. "Funcionando na base dessa falsa expectativa, ela é uma escola hostil à sua clientela verdadeira, porque, sendo uma escola pública, a sua tarefa é educar as crianças brasileiras a partir da condição em que elas se encontrem" (RIBEIRO, 2018, p. 23). Isso significa, em suas palavras, que:

Nossa escola pública é antipopular porque está organizada de modo a beneficiar a minoria de alunos provenientes dos setores mais afortunados. Ela é uma escola injusta porque prejudica os alunos que mais precisam dela, que são os oriundos das camadas populares (RIBEIRO, 1984, p. 93).

\footnotetext{
${ }^{5}$ A escola primária, na generalidade das jurisdições escolares, se tornou uma referência que envolve a base de uma educação escolar oficial, ou seja, o nível elementar de escolarização. Mesmo não sendo mais a nomenclatura, desde 1971, na legislação brasileira, ainda é menção recursiva para identificar o processo de formação inicial.
} 
Darcy Ribeiro destacava, ainda, que na proporção em que a urbanização e a industrialização cresciam aumentava a carência das escolas. Percebia que, na época, o País pouco valorizava a educação e, em razão disso, faltavam recursos financeiros para serem aplicados, enquanto, em contraponto, eram destinadas verbas significativas para outras esferas públicas, como na edificação, estradas e eletrificação nacional. ${ }^{6}$ Por esta razão, ele denuncia a diminuição do percentual dos gastos federais com a educação: em 1962 eram de 11,2\% e, em 1980, de apenas 5,3\%, fazendo um comparativo entre a diminuição dos gastos com a educação e o aumento com outros gastos (idem, p. 29).

Na condição de Ministro da Educação durante o governo João Goulart (1961-1964) e, com apenas 29 anos, o político pode conferir de perto como os recursos eram destinados para a educação tanto na esfera federal quanto nas redes estaduais de ensino manifestando sua inconformidade em relação à atuação e desrespeito de alguns administradores quanto à distribuição desigual dos recursos públicos.

A situação dos educadores também era preocupante. Conforme Ribeiro, por falta de estruturação da carreira profissional os educadores tinham sobrecarga de trabalho, baixa remuneração e se sentiam desestimulados e não suficientemente qualificados para exercerem suas funções. Suas críticas e desabafos mais contundentes dizem respeito à dificuldade de democratizar o ensino público, à falta de incentivo aos professores, à má aplicação dos recursos financeiros e aos gastos com materiais didáticos e audiovisuais na tentativa de promover a modernização do sistema educacional. Em relação ao papel do professor, Darcy Ribeiro argumenta:

É preciso que se diga com toda clareza que nada há de mais simples, nem de mais econômico, nem de mais eficaz e acessível do que a educação com uma boa professora primária. Foi ela só, com seu quadro-negro e suas caixas de giz, que educou o mundo. Evidentemente, a professora pode ser ajudada por meios extra-escolares, mas é ainda ela a única e insubstituível força educativa com que se pode contar (1984, p. 33).

Em sua obra aponta com clareza e espírito crítico as feridas da realidade da educação e, de igual forma, registra e manifesta seu descontentamento em relação à forma como as questões da educação brasileira são enfrentadas.

Darcy Ribeiro assevera que grande parte da calamidade da educação provém de razões históricas e atuais; dentre elas, do próprio caráter autoritário e centralizador da sociedade brasileira, na qual a classe dominante decide sobre os direitos da classe trabalhadora e não leva em conta as necessidades coletivas. Esse quadro tem origem desde a Colônia, passa pelo Império e chega até os dias da atual República, sem que nunca tenha sido enfrentado com a devida seriedade. "Assim se entende que tenhamos um vastíssimo sistema educacional que não educa, bem como portentosos serviços de assistência e previdência social que funcionam na mentira. Em resumo, que em tudo que serve ao povo, sejamos campeões de ineficácia" (RIBEIRO, 2018, p. 25).

Essa tese ilustra, de forma muito clara, seu sentimento e concepção sobre a educação e a sociedade brasileira. Nosso drama educacional trata-se de "uma deficiência intrínseca da sociedade brasileira" (RIBEIRO, 2018, p. 24). As causas de nosso fracasso educacional, portanto, embora se manifestem na atualidade com a indiferença dos gestores, têm raízes em nosso passado Colonial e Imperial, quando poucas vezes se quis alfabetizar alguém ou mesmo educar o povo. Neste sentido, cumpre-se reconhecer que na esfera recente do Brasil República esta tarefa ainda está por se fazer. Conforme advoga Ribeiro, todavia, é preciso fazer um

\footnotetext{
${ }^{6}$ Darcy Ribeiro considera a educação uma questão social, e esse foi sempre um grande problema à medida que, em meados do século 20, o Brasil deixa de ser uma sociedade agrária e evolui para uma sociedade industrial.
} 
diagnóstico profundo - reconhecendo a calamidade -, o que não cria falsa margem para nossa indiferença ou pessimismo vazio, tampouco para nosso voluntarismo ou otimismo ingênuo. Trata-se, isto sim, de um otimismo crítico, que, reconhecendo a dimensão social e histórica do problema educacional no Brasil, o coloca nos termos de nossa possibilidade de enfrentá-lo dentro das condições de uma agência que, efetivamente, põe a República, ou o Estado Brasileiro, a serviço do povo.

Em tom pessimista, Darcy Ribeiro reconhece que "o fracasso brasileiro na educação nossa incapacidade de criar uma escola pública generalizável a todos, funcionando com o mínimo de eficácia - é paralelo à nossa incapacidade de organizar a economia para que todos trabalhem e comam" (1984, p. 47). Esta tonalidade pessimista no diagnóstico movimenta uma agência otimista na ação, tanto que ela se manifesta no testemunho que dá quando se coloca no esforço de pensar e projetar a Lei $n^{\circ}$ 9.394/96, sancionada quando ele estava na condição de Senador da República, no período de 1991 a 1997.

\section{Darcy Ribeiro e a Lei de Diretrizes e Bases da Educação Nacional}

O antropólogo em questão escreve sobre os problemas da educação não como um homem pessimista, mas como uma pessoa que tinha um otimismo radical: vai até a raiz do problema, procura mudar a situação e enfrenta tudo até ser resolvido. Percebe-se a sua profunda preocupação com a situação da educação brasileira ao escrever que "a educação é uma das causas da minha vida. Por isso mesmo, falo dela sempre emocionado, com o coração na boca" (1984, p. 7).

Ao observar a precariedade da escola da sua época, especialmente da esfera pública, sentiu-se no compromisso de reverter essa situação. Nesse sentido, acentua que:

Qualquer avaliação séria da rede educacional brasileira leva à constatação de que, além de tão enorme e tão precária, ela vem se deteriorando gravemente nos últimos anos. As pessoas da minha geração dão testemunho de que as escolas em que estudaram eram muito melhores do que as atuais (RIBEIRO, 1984, p. 23).

Darcy Ribeiro assume, então, a direção da Divisão de Estudos Sociais do Centro Brasileiro de Pesquisas Educacionais e, com o apoio da Unesco organiza um curso de pósgraduação para formar pesquisadores sociais. Em seguida, tornou-se vice-diretor do Instituto Nacional de Pesquisas Educacionais (INEP).

No entanto, além da carreira de professor, pesquisador e escritor, Darcy Ribeiro se dedicou, no Brasil e no exílio, à construção de novas universidades que, geralmente, tinham em comum o objetivo de germinarem mudanças, rompendo com um status quo ultrapassado. [...] Assim, foi no Brasil, com a Universidade de Brasília e a Universidade Estadual do Norte Fluminense (UENF) e, no exílio, com a Universidade Nacional da Costa-Rica e a Universidade de Argel (GOMES, 2005, p. 65-66).

Junto com Anísio Teixeira, colaborou na execução do primeiro Plano Nacional de Educação, cuja finalidade era oferecer uma universidade com um ciclo de formação básica comum aos seus alunos a exemplo dos Centros Integrados de Educação Pública (CIEPs). Darcy Ribeiro pretendia contemplar um novo humanismo, compatível com a sociedade tecnológica, 
tendo como base a pesquisa aplicada, em que o aluno, ao aprender a aprender, pudesse adquirir competência para uma carreira profissional.

Eleito Senador em 1990, Ribeiro atua com destaque na aprovação do Projeto de Lei de Diretrizes e Bases da Educação Nacional que estava tramitando na Câmara desde 1988. Num período em que sua saúde se debilitava, pois sofria de câncer, dedicou-se a organizar a universidade aberta do Brasil, com cursos de Educação a Distância visando à democratização da educação.

A lei atual vigente no Brasil — Lei de Diretrizes e Bases da Educação Nacional no 9.394/96 - , que regulamenta a organização e o funcionamento do ensino em todos os níveis, leva o nome de "Lei Darcy Ribeiro", em homenagem ao seu criador e organizador. A Lei foi sancionada pelo Presidente da República Fernando Henrique Cardoso, em 20 de dezembro de 1996.

A Lei $n^{\circ}$ 9.394/96 trouxe algumas inovações em relação às leis anteriores; dentre elas a unificação dos três níveis de ensino e muitas mudanças, como a inclusão da educação infantil (creches e pré-escolas) como primeira etapa da educação básica. Fruto de longos debates na Câmara dos Deputados, no Senado e em diversas entidades, gerando muita polêmica, pois, na visão de alguns, a atual legislação é omissa em relação a alguns temas, contempla aspectos considerados já ultrapassados e não é tão democrática quanto poderia ser.

\section{A educação brasileira no início do século 21}

A análise e constatação de Darcy Ribeiro em A nossa escola é uma calamidade (1984) sobre a realidade da educação brasileira, com ênfase na educação primária nas duas últimas décadas do século 20, comprova, mais uma vez, que o estado de crise da educação, na qual estamos mergulhados até hoje, parece ser a regra e não a exceção. Os grandes problemas repetem-se e se perpetuam. As soluções tardam e sempre são sonhos adiados.

Ao traçarmos uma análise comparativa, podemos afirmar que melhoramos e, até, superamos alguns dos pontos cruciais apontados por Darcy Ribeiro, mas acrescentamos outros tantos novos e mais graves, talvez. Não há como fazer referência à democratização do ensino e a uma educação republicana, que são as grandes bandeiras de luta deste educador, quando observamos a realidade do sistema educacional brasileiro em todos os níveis e redes de ensino. A democratização da educação e da escola brasileira pode ser analisada com base em três dimensões e critérios: a) do ponto de vista da gestão e organização da escola; $b$ ) do ponto de vista do acesso, da permanência e do percurso na escola e c) do ponto de vista da democracia cognitiva.

$\mathrm{O}$ processo de gestão e organização da escola, especialmente nas redes pública, estadual e municipal, a partir da promulgação da Lei $\mathrm{n}^{0} 9.394 / 06$, passou a ser exercido por diretores eleitos. A escola, no entanto, ainda está atravessada por gestão instituída por órgãos superiores e com pouca autonomia administrativa.

A realidade do Brasil nos últimos anos, do ponto de vista do acesso, da permanência e do percurso na escola, revela-se como uma grande pirâmide invertida. $\mathrm{O}$ acesso ainda não está garantido para todos, sobretudo para aqueles que residem em locais mais afastados, como a zona rural. Da mesma forma a qualidade social da educação ainda não está garantida de forma igualitária para todas as classes sociais.

De acordo com o Anuário Brasileiro da Educação Básica de 2018 é possível constatar, em 2016, a partir das informações sobre matrículas, que dos 48.8 milhões de crianças matriculadas no Brasil, 5.2 milhões estão no campo, 232, 7 mil estão na educação indígena e 218, 4 estão em escolas de áreas quilombolas. O número de crianças fora da escola passou de cinco milhões em 2005 para 2.5 milhões em 2015. Tivemos, portanto uma redução do quadro deficitário e excludente no último período (2005-2015), o que é altamente positivo, mas ainda há um número significativo de crianças e jovens fora da escola. 
O Anuário Brasileiro da Educação Básica de 2019, por sua vez, levanta justamente a questão de que no dia 25 de junho de 2019, fecham cinco anos desde a aprovação do Plano Nacional de Educação (PNE) e que, apesar dos avanços no período 2005-2015, temos certa estagnação e lentidão, mostrando que o ritmo de mudança da realidade educacional está muito aquém do desejado. ${ }^{7}$ Isso demonstra que a educação não foi assumida de um ponto de vista estratégico no último período, como um projeto de nação, como asseverava Darcy Ribeiro.

Embora a universalização do ensino fundamental esteja bem avançada, quase um quarto dos alunos termina o ensino fundamental com mais de 16 anos. Isso de certa forma impacta no Ensino Médio, o qual vem incluindo mais jovens (91, 5\% dos jovens entre 15 e 17 anos estão na escola), mas apenas $68,7 \%$ frequentam essa modalidade de ensino. ${ }^{8}$ Aspecto que explicita as grandes dificuldades de promover igualdade educacional em um país com tanta desigualdade social.

O direito à Educação de qualidade ainda está longe de ser assegurado e se configura no desafio mais urgente. Menos da metade dos alunos atingiram níveis de proficiência considerados adequados ao fim do $3^{\circ}$ ano do Ensino Fundamental em Leitura e Matemática. Na Escrita, os níveis de proficiência também estão distantes do razoável: $33,8 \%$ dos alunos encontram-se em níveis insuficientes (ANUÁRIO BRASILEIRO DA EDUCAÇÃO BÁSICA, 2019, p.14).

Este dado por si já é assustador, mas ele se torna mais preocupante, do ponto de vista da desigualdade, quando as questões de renda, classe social e localização emergem na análise. Em relação à alfabetização em leitura, 29, $8 \%$ das crianças da zona rural atingem um nível suficiente, enquanto que o mesmo nível é alcançado por $47,7 \%$ das crianças que estudam na zona urbana. $\mathrm{Na}$ zona rural o analfabetismo ainda atinge cerca de $17,5 \%$ da população "sendo duas vezes maior para pretos e pardos" (idem, p. 83). Do ponto de vista do Nível Socioeconômico (NSE), enquanto que apenas 14, $1 \%$ das crianças do NSE muito baixo possuem nível suficiente de alfabetização em leitura, "este número chega a $83,5 \%$ das crianças no grupo de NSE muito alto" (ibidem). Essa análise ganha contornos mais problemáticos em 2018, se considerarmos ainda que o ensino integral, que poderia ser um caminho para reverter tal quadro, reduziu em quase $35 \%$ o número de matrículas quando comparamos 2017-2018 (ibidem).

\footnotetext{
${ }^{7}$ Cabe assinalar que dos 27, 2 milhões de crianças que estavam no ensino fundamental, em 2018, cerca de $80 \%$ estavam na escola pública. A taxa líquida de matrícula em 2018 atinge 98\%, sendo superior a de 2012 que alcançou 96, $6 \%$. Há, no entanto, desigualdades regionais, de classe e de renda, o que configura que alguns têm melhores condições de ter sucesso na educação do que outros, em função de sua realidade. O Anuário Brasileiro da Educação Básica (2019) exemplifica isso ao afirmar que: " $68,1 \%$ dos adolescentes da região Norte concluem o Ensino Fundamental com 16 anos, contra 81,9\% no Sudeste” (2019, p. 34). Estas informações também se mostram quando a questão se refere à alfabetização, aprendizagem da leitura e da escrita, bem como matemática entre 2014-2016. Enquanto no Brasil, a porcentagem que atingiu o nível suficiente foi de $45,5 \%$ em alfabetização matemática, este dado chega a 57, 3 na região sudeste e apenas 29, 3 na região norte. Em Minas Gerais 62, 2 \% das crianças atingiram nível suficiente de alfabetização matemática, enquanto apenas 19,5 no Amapá. Quadro que contrasta e mostra as desigualdades regionais e a dificuldade de educar em regiões mais pobres e pauperizadas.

${ }^{8}$ Cumpre destacar a desigualdade nesta etapa de ensino. Segundo o Anuário Brasileiro da Educação Básica (2019, p. 38), “43,3\% dos jovens concluem o Ensino Médio aos 19 anos na Bahia. Essa proporção é de 78,3\% em São Paulo". Há uma presença maior de jovens brancos na escola de nível médio, chegando este número a ser de $11 \%$ acima do que o número de matrículas de jovens negros. Esta expressão numérica evidencia o panorama de fundo da realidade brasileira em sua constituição como país e povo. Os quatro séculos de escravidão, e as realidades desiguais dos sujeitos e das regiões configuram o panorama que se mostra na educação. Há resultados a comemorar em meio aos entraves, mas há ainda muito por fazer. Em 2012, apenas 51, 7 \% concluíam o Ensino Médio. Hoje este número atinge por volta de 63, 6\% (IDEM, p. 40).
} 
O acesso à educação básica está garantido para algo em torno de $95 \%$ da população, porém a média de escolaridade do povo brasileiro é de 6.8 anos. Em relação à população entre 18 a 29 anos, esta média atinge 11,3 anos, sendo de 9,6 na população rural. Se considerarmos o nível de educação infantil (3 a 4 anos), a média de acesso não chega a 80\% (AGÊNCIA BRASIL, 2017). Quase 30\% dos adolescentes e jovens brasileiros não ingressam no ensino médio, na faixa escolar adequada. A nossa escola, portanto continua excludente e elitista.

Apenas algo em torno de $15 \%$ a $18 \%$ dos estudantes brasileiros, entre 25 e 34 anos, estão no ensino superior. ${ }^{9}$ Em relação à desigualdade no acesso ao ensino superior no Brasil, a disparidade entre os estados é uma das mais drásticas. Enquanto 35\% dos jovens de 25 a 34 anos, no Distrito Federal, frequentam a universidade, no Maranhão a taxa é cinco vezes menor (7\%) (AGÊNCIA BRASIL, 2017).

As turmas podem até começar completas, mas terminam em menos da metade. É o que revela o Censo da Educação Superior (MEC; INEP, 2016): 49\% dos alunos abandonaram o curso para o qual foram admitidos. Uma das principais causas, e que forma um círculo vicioso é a deficiência da formação anterior. Desde 2005, ano em que o Índice de Desenvolvimento da Educação Básica (IDEB) foi criado, a nota do ensino médio brasileiro nunca ficou acima de 3,8 na escala de 1 a 10. O desempenho inadequado nas provas de Leitura e Interpretação de Textos e de Matemática pesa bastante. A evasão verificada no ensino superior atingiu, em 2016, 30,18\% na rede privada e $18,5 \%$ na rede pública. Até mesmo em Educação a Distância $(\mathrm{EaD})$ a evasão gira em torno de $30 \%$, e o crescimento da $\mathrm{EaD}$, que teve alta expressiva, fica por conta da crise econômica, da facilidade de obtenção do diploma e do avanço de novas tecnologias.

Além disso, atualmente sobram vagas na educação superior: em 2015, dos 8,5 milhões de vagas disponíveis, apenas 42,1\% foram preenchidas. Conforme o censo do MEC; INEP, 2016, existe mais de 140 mil vagas ociosas na rede federal de ensino e um total maior ainda na rede privada confessional ou empresarial. A rede federal raramente oferece vaga no turno da noite. Sobre a situação dos docentes, chama a atenção também o abandono de cursos de formação de professores. Em 2014, o nível de evasão no curso de Pedagogia chegou a 39\%, e em Física, Química e Matemática houve ainda mais desistências: 57,2\%,52,3\% e 52,6\%, respectivamente.

Dados mostram que a metade dos professores da educação básica ministra aulas de Matemática sem formação específica. Nas áreas da Física, Filosofia, Sociologia e Artes, os números são ainda mais baixos. O percentual de vagas ocupado por professores sem graduação, nessas áreas, é de 32,7\%, 31\%, 18,6\% e 17,2\%, respectivamente (MEC/2017). Considera-se que muitos professores são designados, para não dizer obrigados, a ministrar disciplinas para as quais não são habilitados. A remuneração dos professores continua baixa se comparada com profissionais com o mesmo nível de formação.

\footnotetext{
${ }^{9}$ Esses dados, em 2018, quando o corte é feito entre 18 a 24 anos, atingem 21, 8\% em comparação com 2012 que eram de 16, 6\%; ou seja, nesta faixa etária, houve um aumento do acesso dos jovens ao ensino superior, embora, apenas $7 \%$ provêm do estrato composto por pobres e $48 \%$ por jovens ricos. "Em 2018, as taxas bruta e líquida de matrícula na Educação Superior voltaram a crescer após a queda que apresentou em 2017, embora a meta do PNE esteja ainda distante de ser cumprida. No último ano da série apresentada, o Brasil possuía uma taxa bruta de matrículas de nível superior de $44,2 \%$, acréscimo de 3,9 pontos percentuais em relação a 2017 e de 11,4 pontos percentuais em comparação a 2012. A taxa líquida de matrículas alcançou 21,8\%, em 2018, o que representou avanços de 1,9 e 5,2 pontos percentuais, em relação a 2017 e 2012, respectivamente. Vale notar que o crescimento mais recente reforçou a desigualdade. Enquanto três em cada dez brancos chegam às universidades, 1,5 brasileiro de cor preta a cada dez alcança o nível superior" (ANUÁRIO BRASILEIRO DA EDUCAÇÃO BÁSICA, 2019, p. 98).
} 
A rede privada responde por $75,3 \%$ dos alunos do ensino superior, contra $24,7 \%$ das entidades estatais. Isso significa que, em 2016, havia 6.058.623 estudantes matriculados em faculdades e universidades particulares e outros 1.990.078 em instituições geridas pelo poder público. Quando analisados os dados de 2006 a 2016, o acréscimo de matrículas ficou em $66,8 \%$ no setor privado e $59 \%$ nas redes municipais, estaduais e federais de ensino superior. [...] Existem 2.407 instituições de ensino superior no Brasil. Dessas, 2,1 mil são da iniciativa privada, enquanto 298 são públicas. Para cada aluno matriculado na rede estatal, há 2,5 estudando em instituições particulares, quando se trata de cursos presenciais (AGÊNCIA BRASIL, 2017).

Hoje, cerca de $75 \%$ dos estudantes brasileiros no ensino superior estão em instituições privadas, e isso significa que muitos jovens não podem cursar esse nível por falta de condições econômicas. Em 2017 havia 8.286.663 de matrículas na educação superior no Brasil, destas 6.241.307 foram na rede privada e 2.045.356 na rede pública (ANUÁRIO BRASILEIRO DA EDUCAÇÃO BÁSICA, 2019, p.100).

A análise da dimensão do ponto de vista da democracia cognitiva, compreensivelmente não recebeu a devida importância por parte de Darcy Ribeiro. Esta dimensão, entretanto, é tão ou mais importante e grave do que as demais. Os índices atuais de avaliação, interna e externa, estão atestando o baixo rendimento escolar, ou seja, embora o aluno frequente a escola, os indicadores demonstram que ele não tem uma aprendizagem significativa, e isso é explicado por diversos e diferentes fatores. O aluno é excluído da escola pela própria escola. Dentre os fatores que estão causando a exclusão do aluno são apontados: conteúdos assépticos, metodologias inadequadas, professores desmotivados e escolas sucateadas. Como superar essa situação que é, a nosso ver e também constatação de muitos intelectuais, filósofos e pedagogos, a mais grave de todas: a necessidade de uma profunda reforma paradigmática da educação ${ }^{10} \mathrm{e}$ não apenas pragmática e/ou operacional? Pouco adianta equipar a escola, ampliar a obrigatoriedade/compulsoriedade escolar, fornecer atendimento à saúde e alimentar e, até mesmo, outras medidas compensatórias, se não conseguimos realizar uma adequada democratização do conhecimento e uma ampla reforma do pensamento.

Outra categoria de análise que não estava presente nos textos de Darcy Ribeiro é a questão das Tecnologias Digitais de Informação e Comunicação (TDCIs). Há teses analisando a questão da educomunicação e, até mesmo, de ciberautocidadão. A democratização das tecnologias está sendo colocada como um dos caminhos para despertar e promover outros níveis de cidadania.

Em um passado recente, as tecnologias eram instrumentos utilizados para a leitura e distribuição de conteúdos do tipo midiáticos; hoje, entretanto, servem para a pesquisa, produção, criação e socialização de conteúdos, práticas sociais e processos de subjetivação, ou seja, ela enseja uma outra articulação de linguagens (MARQUES, 2006). Esta revolução é comparável aos grandes inventos da história da humanidade. Essa nova realidade está exigindo mais cuidado e investimento, como destacam muitos pedagogos e educadores. Antônio Nóvoa (2017), para ficar

\footnotetext{
${ }^{10} \mathrm{~A}$ temática da reforma de pensamento é recorrente em várias das obras de Edgar Morin, pois, segundo ele, a reforma das mentes é um pressuposto para um pensar complexo e, portanto, condição sine qua non para a mudança. $\mathrm{O}$ pensamento complexo constitui-se em embasamento teórico para uma reforma do pensamento ou das mentalidades, que é imprescindível para a reforma do conhecimento, a reforma do sistema educacional e a reforma das instituições. As reformas são interdependentes entre si; não podem andar separadas e, deste modo, alimentam e se realimentam umas das outras em um movimento recursivo (MORIN, 2000). A importância e a necessidade das reformas para a metamorfose do homem e da humanidade é também tema central do livro A via para o futuro da humanidade (MORIN, 2013).
} 
apenas em um nome, é enfático ao referir-se à importância da revolução digital, do conhecimento e da conectividade do século 21. Quando perguntado sobre qual é o maior desafio da educação hoje, ele não hesita em afirmar: é a revolução digital. Vivemos numa sociedade tecnoinfocomputrônica, um misto de tecnologia, informática e eletrônica.

Temos excesso de informação que não se traduz em conhecimento. É necessário saber acessar e processar tais informações. Os fatos, os dados, as notícias, são disponibilizadas em forma de publicações físicas ou on-line. No passado as informações eram precárias: hoje, há um excesso delas e é preciso saber selecioná-las e processá-las. Nesse ínterim, precisamos nos precaver e sempre questionar se o fato é fake news e, até mesmo, sobre a veracidade de montagens fotográficas, que podem ser falsas. Para haver conhecimento é preciso saber processar essas informações. De acordo com Valente (2005, p. 24), “o que é passado é a informação que advém desse conhecimento, porém, nunca o conhecimento em si”. Apropriarse de informações e transformá-las em conhecimento, com o uso de diferentes metodologias, é um dos desafios atuais da educação.

Sensível a esse cenário novo Edgar Morin narra no livro Um ano Sísifo (2012, p. 311), um diálogo que encontrou numa revista sobre sabedoria Hindu e que faz referência ao jejum dietético e ao jejum mental, e escreve sobre o nosso tempo: "alimentamo-nos de um excesso de informações, de impressões, de mil coisas inúteis, daí a necessidade do jejum mental por meio da meditação." Precisamos nos submeter a um processo de desintoxicação. Hoje, um dos saberes é saber se proteger de tanta informação, pois elas podem produzir também cegueira e ignorância.

A mediação das TDCIs ${ }^{11}$ é algo que está merecendo debates profundos no presente estágio da educação. Ocorre que o uso e a disponibilização das TDCIs dão sinais de que está sendo produzido um outro modo de exclusão: a exclusão digital. A criação de Programas oficiais dos governos como o Programa Nacional de Tecnologia Educacional (PROINFO), em 1997, e o Programa Banda Larga nas Escolas, em 2008, é uma das preocupações até mesmo das diretrizes curriculares nacionais. Eles atingem pequeno número de estudantes e são colocados à disposição das escolas como uma ferramenta para fins de aprendizagem para o mercado de trabalho, muito mais do que para promover aprendizagens significativas.

Uma das virtualidades da modalidade Educação a Distância deveria ser a democratização do ensino, ou seja: a EaD é uma forma de educação cada vez mais acessível e viável para quem tem interesse em se qualificar, uma vez que permite programar tempos, espaços e ritmos de aprendizagem. Ela possibilita que mais pessoas tenham acesso à educação em diferentes níveis. É atribuição do Estado, ainda, propor políticas públicas capazes de democratizar o acesso às TDCIs em igualdade de condições. Esta democratização, entretanto, enseja, também, grandes desafios pela exclusão e barreira digital que geram ao produzir milhares de analfabetos digitais.

\section{Considerações finais}

Para a compreensão da recente História da Educação do Brasil, é de fundamental importância conhecer a vida e a obra do educador Darcy Ribeiro. Podemos concluir que, na condição de escritor e antropólogo, Ribeiro publicou obras significativas para a percepção e

\footnotetext{
${ }^{11} \mathrm{Na}$ sua última fase de educador e gestor da educação, embora a presença do mundo virtual e digital não era algo tão instigante, Darcy Ribeiro, como um estudioso e de olhar atento, preocupava-se com a presença de novas tecnologias na educação. É dele, inclusive, o projeto de universidade aberta do Brasil, em parceria com Pedro Demo, na qual "[...] pretendia utilizar plenamente as novas tecnologias da informação e da comunicação para abrir as portas dos estudos superiores" (GOMES, 2005, p. 89).
} 
análise do processo civilizatório do Brasil; na condição de educador, teve atuação destacada como gestor e criador de projetos inovadores e de Universidades, tanto no Brasil quanto no exterior; e, na participação política, teve oportunidade de influenciar na elaboração e aprovação da última e mais completa Lei de Diretrizes e Bases da Educação Nacional (Lei n ${ }^{\circ}$ 9.394/96).

É evidente que, nas duas primeiras décadas do século 21, temos uma realidade mais complexa e com novos desafios, como é o caso da TDCI e a modalidade de EaD. A questão da democratização da educação ainda continua, sem dúvida, como uma meta a ser cumprida no que diz respeito ao acesso, permanência e percurso com êxito em todos os níveis de ensino, bem como na questão da exclusão escolar provocada, entre outros fatores, pelas barreiras sociais e por aquelas que a própria escola institui. Ainda é oportuno observar o que Darcy Ribeiro escreveu sobre a necessidade tanto da educação básica quanto da superior: "Só uma e outra, devidamente conjugadas, habilitam um povo a ingressar na civilização moderna” (1984, p. 77).

\section{Referências}

AGÊNCIA BRASIL. 2017. Disponível em http://agenciabrasil.ebc.com.br/internacional/2017. Acesso em: $1^{\circ}$ out. 2018.

ANUÁRIO BRASILEIRO DA EDUCAÇÃO BÁSICA. São Paulo: Ed. Moderna, 2018. Disponível em http://www.moderna.com.br. Acesso em 1º de jul. 2019.

ANUÁRIO BRASILEIRO DA EDUCAÇÃO BÁSICA. São Paulo: Ed Moderna, 2019. Disponível em http://www.moderna.com.br. Acesso em 1º de jul. 2019.

BRASIL. Lei 9.394/96: Diretrizes e bases da educação nacional. Brasília: MEC, 1996.

FUNDAÇÃO DARCY RIBEIRO. Biografia. 1996. Disponível em: http://www.fundar.org.br/bibliografia. Acesso em: $1^{\circ}$ out. 2018.

GOMES, Cândido A. Darcy Ribeiro ou a rebeldia na educação. In: GOMES, Cândido A. (org.). Educadores Brasileiros do Século XX: v. 2. Brasília: Liber Livro; Ed. Universidade Católica de Brasília, 2005. p. 53-95.

MARQUES, Mario Osorio. A escola no computador: linguagens articuladas, educação outra. Ijuí: Ed. Unijuí, 2006. (Coleção Mario Osorio Marques; v. 2).

MARTINO, Luís M. S. Teoria das mídias digitais: linguagens, ambientes, redes. Petrópolis: Vozes, 2014.

MEC; INEP. Ministério da Educação; Instituto Nacional de Estudos e Pesquisas Educacionais Anísio Teixeira. Censo da Educação Superior de 2016. Disponível em: https://www.correiobraziliense.com.br. Acesso em: $1^{\circ}$ out. 2018.

MORIN, Edgar. Um ano sísifo. Tradução Edgar de Assis Carvalho e Mariza Perassi Bosco. São Paulo: Edições SESC, 2012.

MORIN, Edgar. A cabeça bem-feita: repensar a reforma, reformar o pensamento. 2. ed. Rio de Janeiro: Bertrand Brasil, 2000.

MORIN, Edgar. A via para o futuro da humanidade. Rio de Janeiro: Bertrand Brasil, 2013. 
NÓVOA, Antônio. Prefácio. In: GUÉRIOS et al. (org.). Complexidade e educação: diálogos epistemológicos transformadores. Curitiba: CRV, 2017.

RIBEIRO, Darcy. Nossa escola é uma calamidade. Rio de Janeiro: Salamandra, 1984.

RIBEIRO, Darcy. O processo civilizatório: etapas da evolução sociocultural. Rio de Janeiro: Companhia das Letras, 1998.

RIBEIRO, Darcy. O povo brasileiro: a formação e o sentido do Brasil. São Paulo: Global Editora, 2014.

RIBEIRO, Darcy. As Américas e a Civilização: processo de formação e causas do desenvolvimento cultural desigual dos povos americanos. Rio de Janeiro: Companhia das Letras, 2007.

RIBEIRO, Darcy. Os índios e a civilização: a integração das populações indígenas no Brasil moderno. São Paulo: Global Editora, 2017.

RIBEIRO, Darcy. O Dilema da América Latina: estruturas do poder e forças insurgentes. Petrópolis: Vozes, 1979.

RIBEIRO, Darcy. Os brasileiros: teoria do Brasil. São Paulo: Editora Civilização Brasileira, 1975.

RIBEIRO, Darcy. Educação como prioridade. Seleção e organização Lúcia Velloso Maurício. São Paulo: Global Editora, 2018.

VALENTE, José A. Pesquisa, comunicação e aprendizagem com o computador. In: BRASIL. Integração das tecnologias na educação. Brasília: Ministério da Educação, 2005. p. 22-31. 